\title{
Making Marble Powder Waste Profitable by Using Nano-TiO Surface Modification for Air Quality Improvement Applications
}

\author{
Yaxiong Ji, ${ }^{1}$ Xing Rong, ${ }^{2}$ Hong Zhong, ${ }^{1}$ Yuanhao Wang, ${ }^{1,3}$ Shifeng Wang, ${ }^{3}$ and Lin Lu ${ }^{1}$ \\ ${ }^{1}$ Renewable Energy Research Group (RERG), Department of Building Services Engineering, \\ The Hong Kong Polytechnic University, Kowloon, Hong Kong \\ ${ }^{2}$ Shenzhen Middle School, Luohu District, Shenzhen, China \\ ${ }^{3}$ Faculty of Science and Technology, Technological and Higher Education Institute of Hong Kong, New Territories, Hong Kong \\ Correspondence should be addressed to Yuanhao Wang; wangyuanhao@vtc.edu.hk and Shifeng Wang; sfwang@vtc.edu.hk
}

Received 28 September 2017; Accepted 1 November 2017; Published 10 December 2017

Academic Editor: Rajesh Adhikari

Copyright (C) 2017 Yaxiong Ji et al. This is an open access article distributed under the Creative Commons Attribution License, which permits unrestricted use, distribution, and reproduction in any medium, provided the original work is properly cited.

\begin{abstract}
We report a brand new recycling route of waste marble powder, by means of surface modification with homemade nano-TiO ${ }_{2}$ particles to produce low cost coating materials for the application in air quality improvement. The as-prepared nano-TiO $\mathrm{O}_{2}$ in anatase phase exhibits excellent photocatalytic characteristic, reflected by the high degradation rate of over $95 \%$ of methylene blue within 6 hours of UV irradiation. The prepared coating consisting of nano- $\mathrm{TiO}_{2}$ clad marble powder was tested by monitoring the decomposition rate of formaldehyde gas. A high degradation efficiency of about $95 \%$ within 9 hours of illumination is achieved, demonstrating a promising potential for removing the harmful and toxic organic pollutants in air while applying this coating in buildings both interiorly and exteriorly.
\end{abstract}

\section{Introduction}

Stones, especially marble, are commonly utilized in buildings and for decoration. However, a tremendous amount of marble powder waste will be produced while cutting and polishing these high numbers of marble raw materials. The micrometer- or submicrometer-sized marble powder is prone to drift into air, polluting the atmosphere by increasing the particulate matter content in air. Additionally, the marble powder can be easily inhaled by local workers and residents, causing serious lung diseases. Recently, awareness of such issue has been raised by the local environment departments of the stone product manufacturing sites, as well as researchers who focus on the recycling applications [1-3].

Nowadays the reuse of the waste marble powder concentrates upon incorporating the waste marble into the traditional construction materials, such as cement and concrete, to tailor their mechanical properties [3-7]. For instance, Aliabdo et al. found a 9\% improvement in the compressive strength of cement when $10 \%$ marble powder was added to it [4]. It was also found that a $16 \%$ enhancement in the tensile strength was observed when $10 \%$ of the sand in the concrete was replaced with marble powder [5]. In addition, Bilgin et al. reported a linear increase in the hardness of the bricks with the content of incorporated marble powder [6].

However, few studies report on the recycling of the marble powder by combining nanomaterials or utilizing nanotechnologies. In this paper, a completely new way to reuse the waste marble powder was introduced, transforming the waste into functional coating with the help of nanomaterials. The milled and screened waste marble powder in micrometer size was clad with homemade highly dispersive nanometersized $\mathrm{TiO}_{2}$ particles and was finally made into a new type of environmentally friendly and low price paint. Owing to the surface modification with the photocatalytic nanomaterial, the paint can decompose harmful and toxic pollutants in air, such as formaldehyde, benzene, volatile organic compounds (VOCs), and nitric oxides $\left(\mathrm{NO}_{x}\right)$ and sulfur oxides $\left(\mathrm{SO}_{x}\right)$ from vehicle exhaust [8-10], improving the air quality of human living environment both interiorly and exteriorly. In addition, the effectiveness of the degradation of hazardous organics by the novel coating materials based on the waste 
marble powder was studied and characterized in this work. Such coating holds a great potential for large-scale applications in buildings.

\section{Materials and Methods}

2.1. Coating Fabrication. Chemically pure (98\% purity) titanium butoxide (TBT) purchased from Aladdin was mixed with ethanol with a massive ratio of $1: 8$ in a $150 \mathrm{ml}$ reaction kettle. Then the reaction kettle was placed into an oven, maintaining a temperature of $160^{\circ} \mathrm{C}$ and a reaction duration of 12 hours. Then the reaction product was filtered, washed, and dried, producing highly dispersive $\mathrm{TiO}_{2}$ nanoparticles, as described in $[3,11,12] .3 \mathrm{~g}$ of the prepared nano- $\mathrm{TiO}_{2}$ was added to $40 \mathrm{~g}$ ethanol and then was sufficiently dispersed by using the ultrasonic bath for about 30 minutes.

The waste marble powder was milled by using a ball grinder and $1 \sim 5 \mathrm{~mm}$ zirconium balls as the milling media. Then the marble powder of large size was reduced into micrometer or submicrometer size, followed by screening with different meshes. $7 \mathrm{~g}$ of the milled and screened marble powder was added to $50 \mathrm{ml}$ ethanol and stirred on a stirrer at a speed of 700 revolutions per minute (rpm). During the stirring, $50 \mathrm{ml}$ of the as-prepared nano- $\mathrm{TiO}_{2}$ dispersion was incorporated into the marble powder dispersion through a constant pressure hopper, at a rate of 5 drops per second. Then the mixture was continuously stirred for another 5 hours. Finally, a novel low cost paint based on the waste marble powder was fabricated.

2.2. Characterizations and Tests. The crystal structures of the materials were characterized by X-ray diffraction (XRD) using a Rigaku Smartlab 9 kW X-ray diffractometer, equipped with a $\mathrm{Cu}-\mathrm{K}_{\alpha 1}$ radiation source $(\lambda=1.5406 \AA)$. Scanning electron microscopy (SEM) was employed to investigate the microstructure of the materials, using a JEOL 6490 microscope at an accelerating voltage of $20 \mathrm{kV}$. The transmission electron microscopy (TEM) images of the as-prepared titanium dioxide were recorded through a JEM-2100F field emission scanning transmission electron microscope equipped with an Oxford INCA x-sight EDS $\mathrm{Si}(\mathrm{Li})$ detector at an acceleration voltage of $200 \mathrm{kV}$. The absorbance variation and degradation of methylene blue solution by the as-prepared nano- $\mathrm{TiO}_{2}$ were carried out by using a Shimadzu UV-1800 spectrophotometer, and the tests followed the standard ISO 10678:2010.

\section{Results and Discussion}

Figure 1 shows the XRD $\theta-2 \theta$ diffraction patterns of the waste marble powder, highly dispersive nano- $\mathrm{TiO}_{2}$ prepared by our research group, and the titanium dioxide coated marble powder, respectively. The upper curve shows the marble powder diffraction peaks, which match well with JCPDS data of rhombohedral structured $\mathrm{CaCO}_{3}$ (Card Number 02-0623), indicating that the waste marble powder mainly consists of $\mathrm{CaCO}_{3}$. According to JCPDS Card Number 01-0562, the middle curve suggests the as-prepared titanium dioxide is

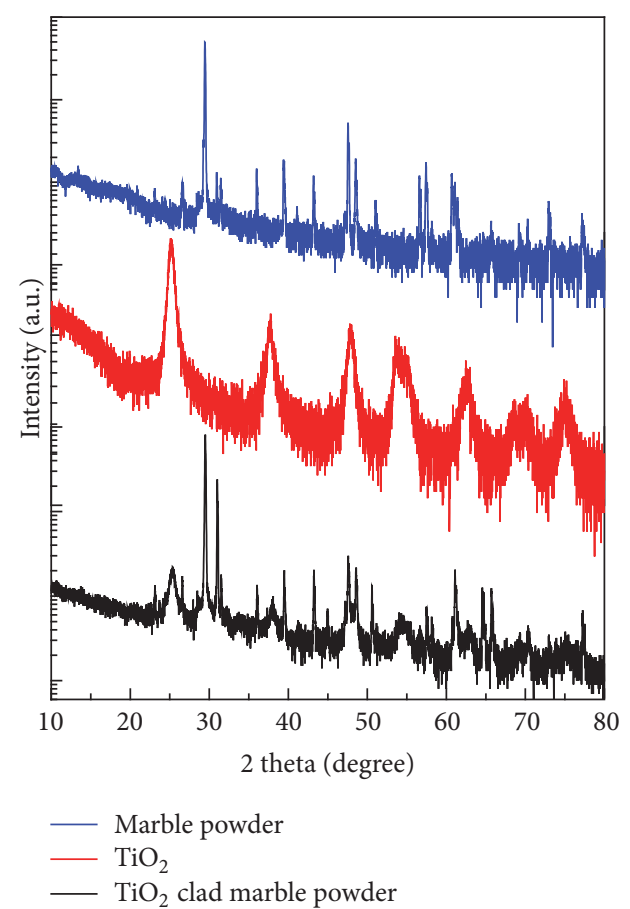

FIGURE 1: XRD spectra of marble powder (upper), as-prepared $\mathrm{TiO}_{2}$ (middle), and $\mathrm{TiO}_{2}$ clad marble powder (lower).

in the form of anatase crystal structure, which possesses highly efficient photocatalytic property [13-16]. The lattice constants are obtained as $a=3.73 \AA, b=3.73 \AA$, and $c=$ $9.37 \AA$, respectively. $\mathrm{Nano}-\mathrm{TiO}_{2}$ in anatase phase, belonging to the wide band gap semiconductor materials [17-19], is extensively applied to the photocatalysis field, also because of its inexpensive, abundant, and nontoxic constituent elements $[14,20,21]$. It is obviously seen that the lower spectrum is a superposition of the upper and middle ones, implying the micrometer- or submicrometer-sized marble powder surface is sufficiently modified with the nano- $\mathrm{TiO}_{2}$. The $\mathrm{TiO}_{2}$ clad marble powder then could decompose the harmful and toxic organic pollutants due to its strong photocatalytic property under sunlight illumination [13-16].

TEM images reveal the microstructure of the as-prepared highly dispersive nano- $\mathrm{TiO}_{2}$, as illustrated in Figure 2. It is observed that the as-prepared $\mathrm{TiO}_{2}$ crystal size is in the scale of several tens of nanometers, as shown in Figure 2(a). In addition, Figure 2(b) indicates that the lattice constant of nano- $\mathrm{TiO}_{2}$ is $3.64 \AA$ on average in the (001) plane, in reasonable agreement with the parameters deduced from the above XRD data. These data confirm the anatase crystal structure of the as-prepared nano- $\mathrm{TiO}_{2}$ particles.

Corresponding to Figure 1, the microstructures and morphologies of the marble powder, nano- $\mathrm{TiO}_{2}$, and $\mathrm{TiO}_{2}$ clad marble powder were also examined by using a JEOL 6490 scanning electron microscope, which is equipped with an energy dispersive spectroscopy detector (EDS), as shown in Figure 3. The waste marble powder was milled or screened, producing micrometer-sized powder, as shown in Figures 3 (a) and 3(b). The elements and their content in the marble 


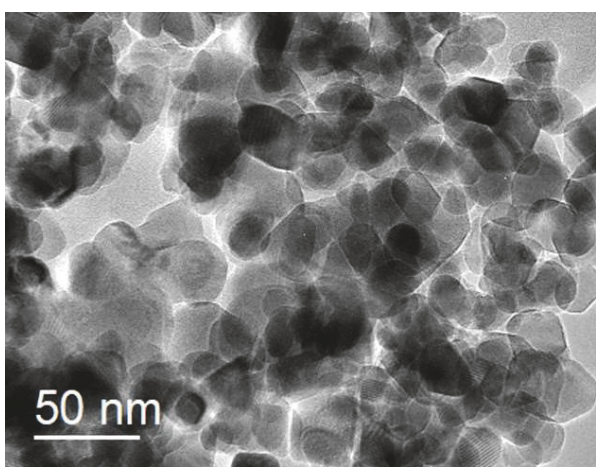

(a)

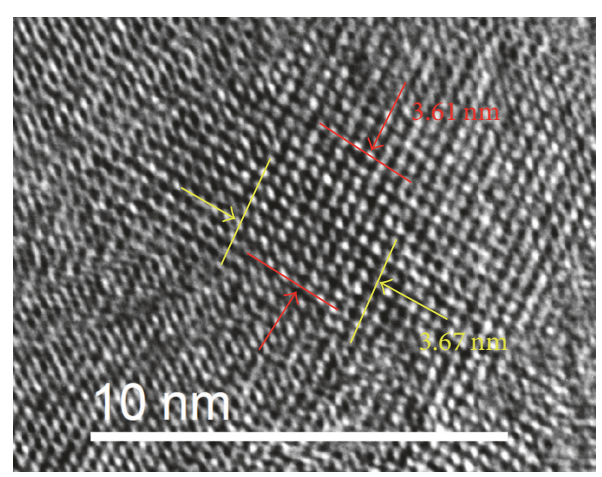

(b)

FIGURE 2: TEM images of the as-prepared nano- $\mathrm{TiO}_{2}$ : (a) bright field image and (b) high resolution image.

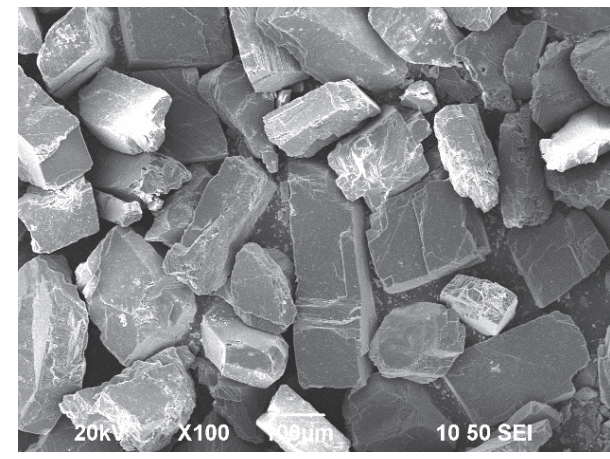

(a)

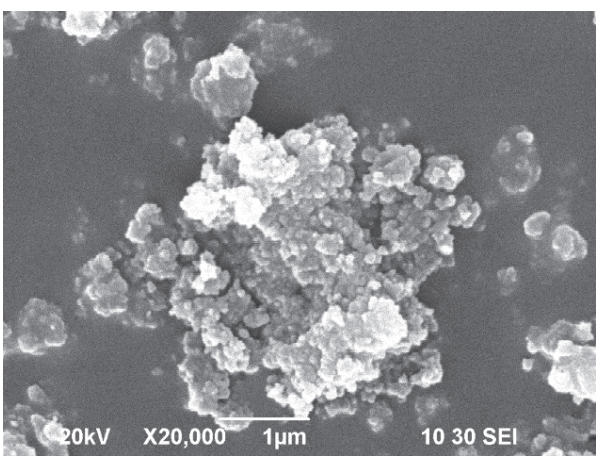

(c)

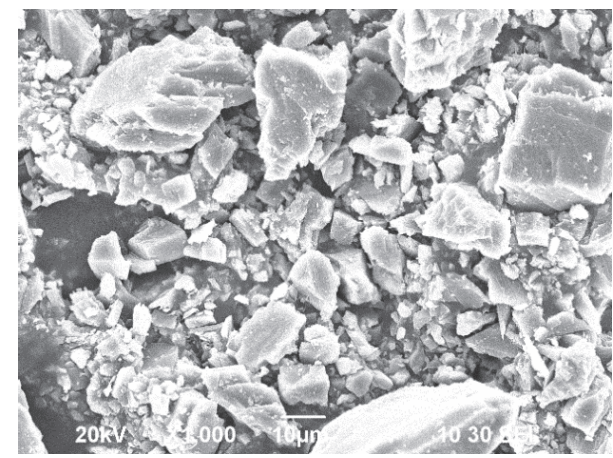

(b)

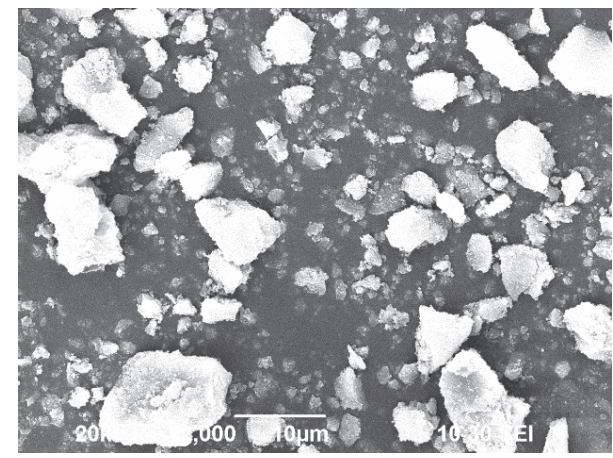

(d)

Figure 3: SEM images of marble powder (a, b), nano- $\mathrm{TiO}_{2}$ (c), and $\mathrm{TiO}_{2}$ clad marble powder (d).

powder were examined by using EDS. As listed in Table 1 , carbon, oxygen, and calcium elements were detected with an atomic ratio of around $18: 54: 25$, confirming that the waste marble powder consists predominantly of $\mathrm{CaCO}_{3}$. It should be noted that the appearance of gold in the testing originates from the gold-coating on the sample surface to facilitate the SEM characterization. Figure 3(c) shows the morphology of the as-prepared $\mathrm{TiO}_{2}$, while the $\mathrm{TiO}_{2}$ clad marble powder is displayed in Figure 3(d). It is confirmed by EDS that the nano- $-\mathrm{TiO}_{2}$ particles are connected to and entirely coated on the micrometer-sized marble powder surface, making an efficient cladding and rough surface to play the full role of the photocatalytic function.
To assess the degradation efficiency of hazardous organics by the prepared nano- $\mathrm{TiO}_{2}$ by way of its photocatalytic activity, a methylene blue degradation test was carried out according to the standard of ISO 10678:2010 [22-25]. Firstly, $0.4 \mathrm{mg}$ methylene blue powder was dissolved sufficiently into $100 \mathrm{ml}$ deionized water, followed by adding $12.5 \mathrm{mg}$ asprepared $\mathrm{TiO}_{2}$ nanoparticles into the solution. Then the mixture was stirred on the magnetic stirrer at a speed of $700 \mathrm{rpm}$ for 30 minutes. Before each measurement of the absorbance between the wavelengths at $500 \mathrm{~nm}$ and $700 \mathrm{~nm}$ performed on the UV-visible spectrophotometer, the solution was illuminated under a UVA lamp with an irradiation wavelength of $365 \mathrm{~nm}$ for 1 hour. Then the degradation percentage 


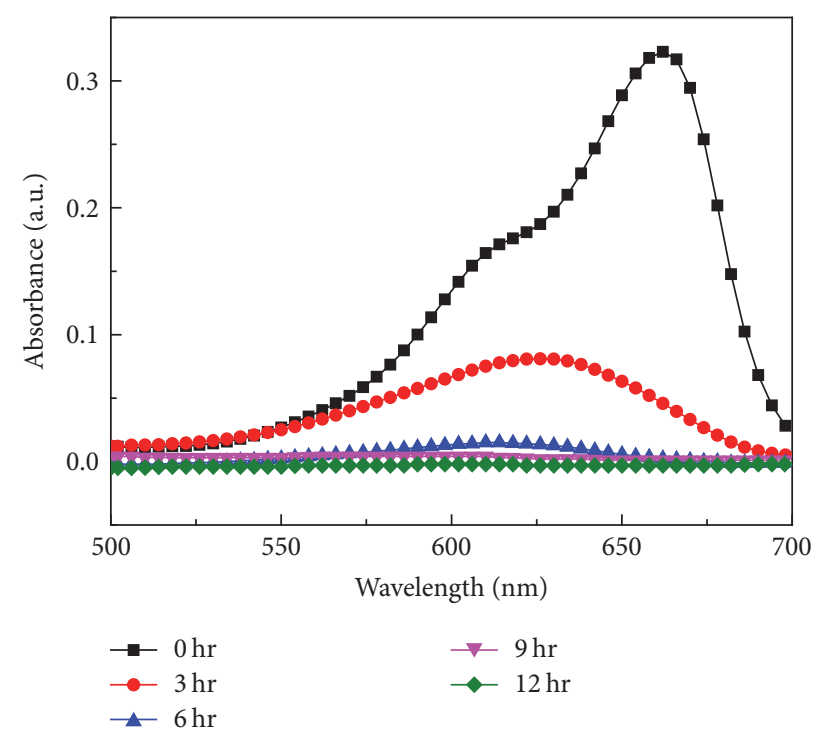

(a)

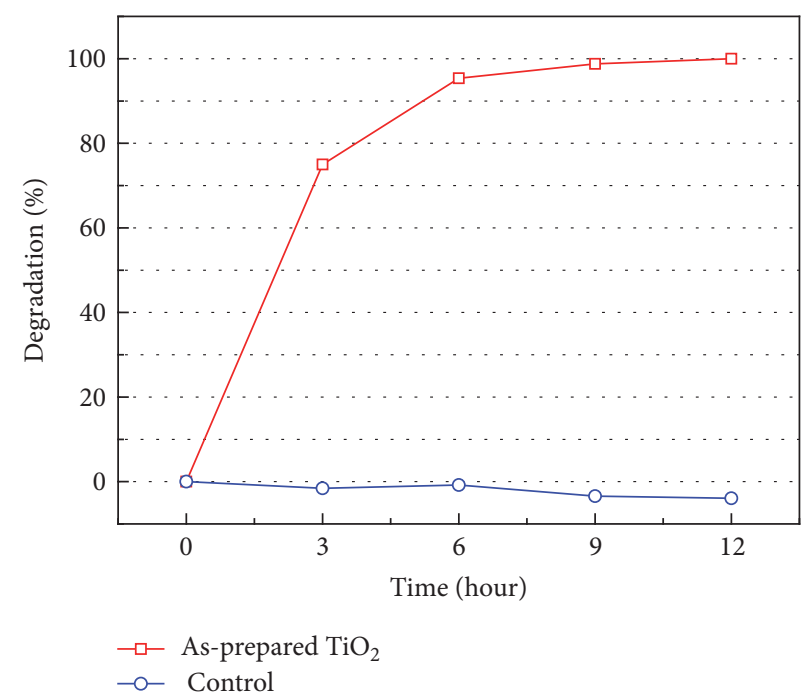

(b)

FIGURE 4: Methylene blue absorption as a function of wavelength at the varying durations (a) and the evaluated degradation efficiency with time (b).

TABLE 1: Elements and their content detected in the marble powder.

\begin{tabular}{|c|c|c|}
\hline Element & Weight $\%$ & Atomic\% \\
\hline $\mathrm{C}$ & 8.82 & 18.32 \\
\hline $\mathrm{O}$ & 34.86 & 54.34 \\
\hline $\mathrm{Ca}$ & 40.78 & 25.37 \\
\hline $\mathrm{Au}$ & 15.54 & 1.97 \\
\hline Totals & & \\
\hline
\end{tabular}

of methylene blue against the duration was derived from the absorbance variation [23]. The dependence of methylene blue absorbance on the wavelength at different duration is plotted in Figure 4(a). It is seen that the light absorption of methylene at wavelength of about $660 \mathrm{~nm}$ is significantly reduced to be negligible when the solution is irradiated under the UVA lamp for about 6 hours. As shown in Figure 4(b), the degradation efficiency reached $95.4 \%$ after 6 -hour irradiation, and the figure was raised to $98.7 \%$ when the duration lasted 9 hours. This test shows a strong photocatalytic property of the as-prepared $\mathrm{TiO}_{2}$ nanoparticles, demonstrating an effective and efficient approach to decompose the hazardous organics around human living environment.

The high performance nano- $\mathrm{TiO}_{2}$ was then incorporated into the micrometer-sized marble powder and finally was made into a type of coating or paint. To evaluate the performances of this coating, a degradation experiment on formaldehyde gas was conducted, simulating the degradation of harmful and toxic gasses while applying this paint in human living environment. First, the paint was coated on three pieces of A5-sized glasses, of which two were vertically placed against the inside walls of a transparent acrylic box with a dimension of $360 \times 160 \times 160 \mathrm{~mm}^{3}$ and the other one lying on the inside bottom of the box. Before testing, four drops of formaldehyde solution with a concentration of $\sim 38.5 \%$ were put on a glass slide, which also lies on the inside bottom of the transparent acrylic box next to the lying A5 sized glass. At the same time, a formaldehyde detector with a Dart 2-FE5 sensor inside was placed on the lying A5 sized glass in the acrylic box. Finally the box was sealed by a transparent acrylic cover with a rubber ring. After the saturation of the evaporated formaldehyde in the box, a UV lamp of 20 Watt power (model number L6274Z) was placed on the box cover and turned on to provide UV illumination, and immediately the data was recorded. Figure 5 shows the variation of formaldehyde concentration with the irradiation duration. A reduction in the formaldehyde concentration is clearly monitored from $2.371 \mathrm{mg} / \mathrm{m}^{3}$ to about $1.109 \mathrm{mg} / \mathrm{m}^{3}$ after 3 hours of irradiation under the UV lamp, corresponding to a degradation rate of $53.2 \%$. The degradation rate reached approximately $95 \%$ after 9 hours and the figure increased to about $98 \%$ after 12 hours of illumination. The experimental data show a high performance on the decomposition of formaldehyde harmful gas. This demonstrates that the novel coating holds great potential for applications in the interior and exterior walls of buildings, effectively decomposing the harmful and toxic pollutants in air and greatly improving the indoor and outdoor air quality.

\section{Conclusions}

The marble powder waste, originating from the stone product manufacturing, would bring severe problems associated with living environment and human health. To recycle the waste in an environmentally friendly and cost effective way and make the waste profitable, a new strategy of incorporating nanomaterials was introduced in this work. A novel coating or paint combining the micrometer-sized waste marble 


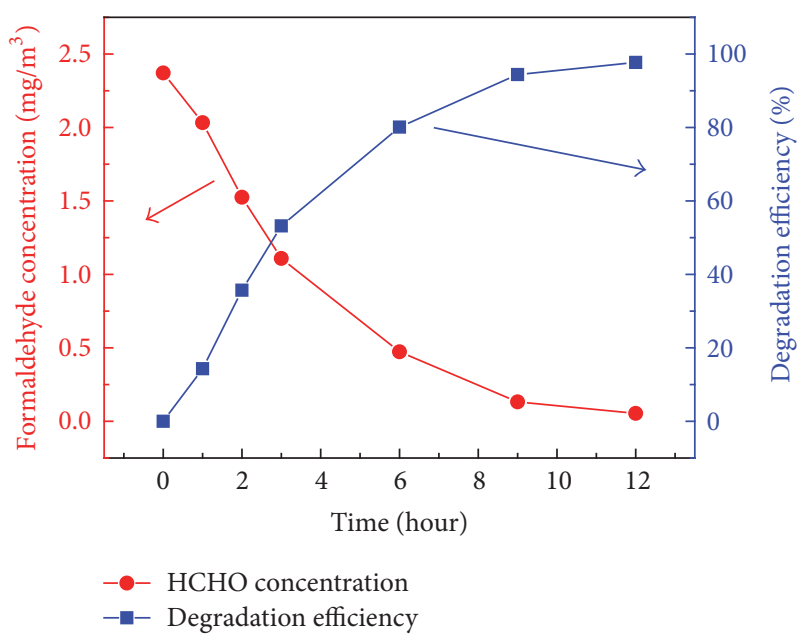

FIGURE 5: The variation of formaldehyde concentration and degradation rate with UV irradiation time.

powder and homemade nano- $\mathrm{TiO}_{2}$ particles was prepared. The as-prepared nano- $\mathrm{TiO}_{2}$ shows anatase crystal network and excellent photocatalytic performance, mirrored by the high degradation rate of methylene blue solution. A formaldehyde-decomposing test was conducted to simulate the degradation of hazardous organics in air while applying the coating on building surfaces. A high degradation efficiency of about $95 \%$ with 9 hours of UV irradiation is achieved, proving the effectiveness in air quality improvement. This novel coating made of waste marble powder and photocatalytic $\mathrm{TiO}_{2}$ nanoparticles has great potential for applications in buildings for purifying the environmental atmosphere.

\section{Conflicts of Interest}

The authors declare that they have no conflicts of interest.

\section{Acknowledgments}

This work is funded by an RGC Grant (UGC/FDS25/E03/15/ 99604). Shenzhen Peacock Plan (KQTD2015071616442225) also supported this work in the material preparation and characterizations.

\section{References}

[1] O. Sivrikaya, K. R. Kiyildi, and Z. Karaca, "Recycling waste from natural stone processing plants to stabilise clayey soil," Environmental Earth Sciences, vol. 71, no. 10, pp. 4397-4407, 2014.

[2] T. Uygunoğlu, I. B. Topçu, and A. G. Çelik, "Use of waste marble and recycled aggregates in self-compacting concrete for environmental sustainability," Journal of Cleaner Production, vol. 84, no. 1, pp. 691-700, 2014.

[3] Y. Wong, L. Tong, Y. Hu, and P. Wu, "A self-assembly and highrobustness super-hydrophobic coating based on waste marble powder," Materials Transactions, vol. 57, no. 12, pp. 2127-2131, 2016.

[4] A. A. Aliabdo, A. E. M. Abd Elmoaty, and E. M. Auda, "Re-use of waste marble dust in the production of cement and concrete," Construction and Building Materials, vol. 50, pp. 28-41, 2014.
[5] A. Ergün, "Effects of the usage of diatomite and waste marble powder as partial replacement of cement on the mechanical properties of concrete," Construction and Building Materials, vol. 25, no. 2, pp. 806-812, 2011.

[6] N. Bilgin, H. A. Yeprem, S. Arslan, A. Bilgin, E. Günay, and M. Maroglu, "Use of waste marble powder in brick industry," Construction and Building Materials, vol. 29, pp. 449-457, 2012.

[7] H. Hebhoub, H. Aoun, M. Belachia, H. Houari, and E. Ghorbel, "Use of waste marble aggregates in concrete," Construction and Building Materials, vol. 25, no. 3, pp. 1167-1171, 2011.

[8] T. Noguchi, A. Fujishima, P. Sawunyama, and K. Hashimoto, "Photocatalytic degradation of gaseous formaldehyde using TiO2 film," Environmental Science \& Technology, vol. 32, no. 23, pp. 3831-3833, 1998.

[9] H. Xie, Y. Zhang, and Q. Xu, "Photodegradation of VOCs by C$\mathrm{TiO}_{2}$ nanoparticles produced by flame CVD process," Journal of Nanoscience and Nanotechnology, vol. 10, no. 8, pp. 5445-5450, 2010.

[10] M. Zeng, Y. Li, M. Mao, J. Bai, L. Ren, and X. Zhao, "Synergetic effect between photocatalysis on $\mathrm{TiO}_{2}$ and thermocatalysis on $\mathrm{CeO}_{2}$ for gas-phase oxidation of benzene on $\mathrm{TiO}_{2} / \mathrm{CeO}_{2}$ nanocomposites," ACS Catalysis, vol. 5, no. 6, pp. 3278-3286, 2015.

[11] Y. Wang, H. Yang, Y. Liu et al., "The use of Ti meshes with self-organized $\mathrm{TiO}_{2}$ nanotubes as photoanodes of all-Ti dyesensitized solar cells," Progress in Photovoltaics, vol. 18, no. 4, pp. 285-290, 2010.

[12] Y. Hu, Y. Wang, Z. An, J. Zhang, and H. Yang, “The super-hydrophobic IR-reflectivity $\mathrm{TiO}_{2}$ coated hollow glass microspheres synthesized by soft-chemistry method," Journal of Physics and Chemistry of Solids, vol. 98, pp. 43-49, 2016.

[13] N. Li, G. Liu, C. Zhen, F. Li, L. Zhang, and H.-M. Cheng, "Battery performance and photocatalytic activity of mesoporous anatase $\mathrm{TiO}_{2}$ nanospheres/graphene composites by templatefree self-assembly," Advanced Functional Materials, vol. 21, no. 9, pp. 1717-1722, 2011.

[14] T. Ohno, K. Sarukawa, K. Tokieda, and M. Matsumura, "Morphology of a $\mathrm{TiO}_{2}$ photocatalyst (Degussa, P-25) consisting of anatase and rutile crystalline phases," Journal of Catalysis, vol. 203, no. 1, pp. 82-86, 2001.

[15] K. Okamoto, Y. Yamamoto, H. Tanaka, and A. Itaya, "Kinetics of heterogeneous photocatalytic decomposition of phenol over anatase TiO," Bulletin of the Chemical Society of Japan, vol. 58, no. 7, pp. 2023-2028, 1985.

[16] H. G. Yang, G. Liu, S. Z. Qiao et al., "Solvothermal synthesis and photoreactivity of anatase $\mathrm{TiO}_{2}$ nanosheets with dominant 001 facets," Journal of the American Chemical Society, vol. 131, no. 11, pp. 4078-4083, 2009.

[17] S. F. Wang, W. K. Fong, W. Wang, and C. Surya, "Growth of highly textured SnS on mica using an SnSe buffer layer," Thin Solid Films, vol. 564, pp. 206-212, 2014.

[18] S. F. Wang, W. Wang, W. K. Fong, Y. Yu, and C. Surya, "Tin Compensation for the SnS Based Optoelectronic Devices," Scientific Reports, vol. 7, Article ID 39704, 2017.

[19] Y. Yu, P. W. K. Fong, S. Wang, and C. Surya, "Fabrication of WS2/GaN p-n Junction by Wafer-Scale WS2 Thin Film Transfer," Scientific Reports, vol. 6, Article ID 37833, 2016.

[20] S. Klosek and D. Raftery, "Visible light driven V-doped $\mathrm{TiO}_{2}$ photocatalyst and its photooxidation of ethanol," The Journal of Physical Chemistry B, vol. 105, pp. 2815-2819, 2001.

[21] T. Ohno, T. Mitsui, and M. Matsumura, "Photocatalytic activity of S-doped $\mathrm{TiO}_{2}$ photocatalyst under visible light," Chemistry Letters, vol. 32, no. 4, pp. 364-365, 2003. 
[22] M. B. Fisher, D. A. Keane, P. Fernández-Ibáñez et al., "Nitrogen and copper doped solar light active $\mathrm{TiO}_{2}$ photocatalysts for water decontamination," Applied Catalysis B: Environmental, vol. 130-131, pp. 8-13, 2013.

[23] A. Mills, "An overview of the methylene blue ISO test for assessing the activities of photocatalytic films," Applied Catalysis B: Environmental, vol. 128, pp. 144-149, 2012.

[24] S. Villa, V. Caratto, F. Locardi et al., "Enhancement of $\mathrm{TiO}_{2} \mathrm{NPs}$ activity by $\mathrm{Fe}_{3} \mathrm{O}_{4}$ nano-seeds for removal of organic pollutants in water," Materials, vol. 9, no. 9, article 771, 2016.

[25] E. M. Moser, S. Chappuis, and J. Olleros, "Production of photocatalytically active titania layers: A comparison of plasma processes and coating properties," Surface and Coatings Technology, vol. 227, pp. 2-9, 2013. 

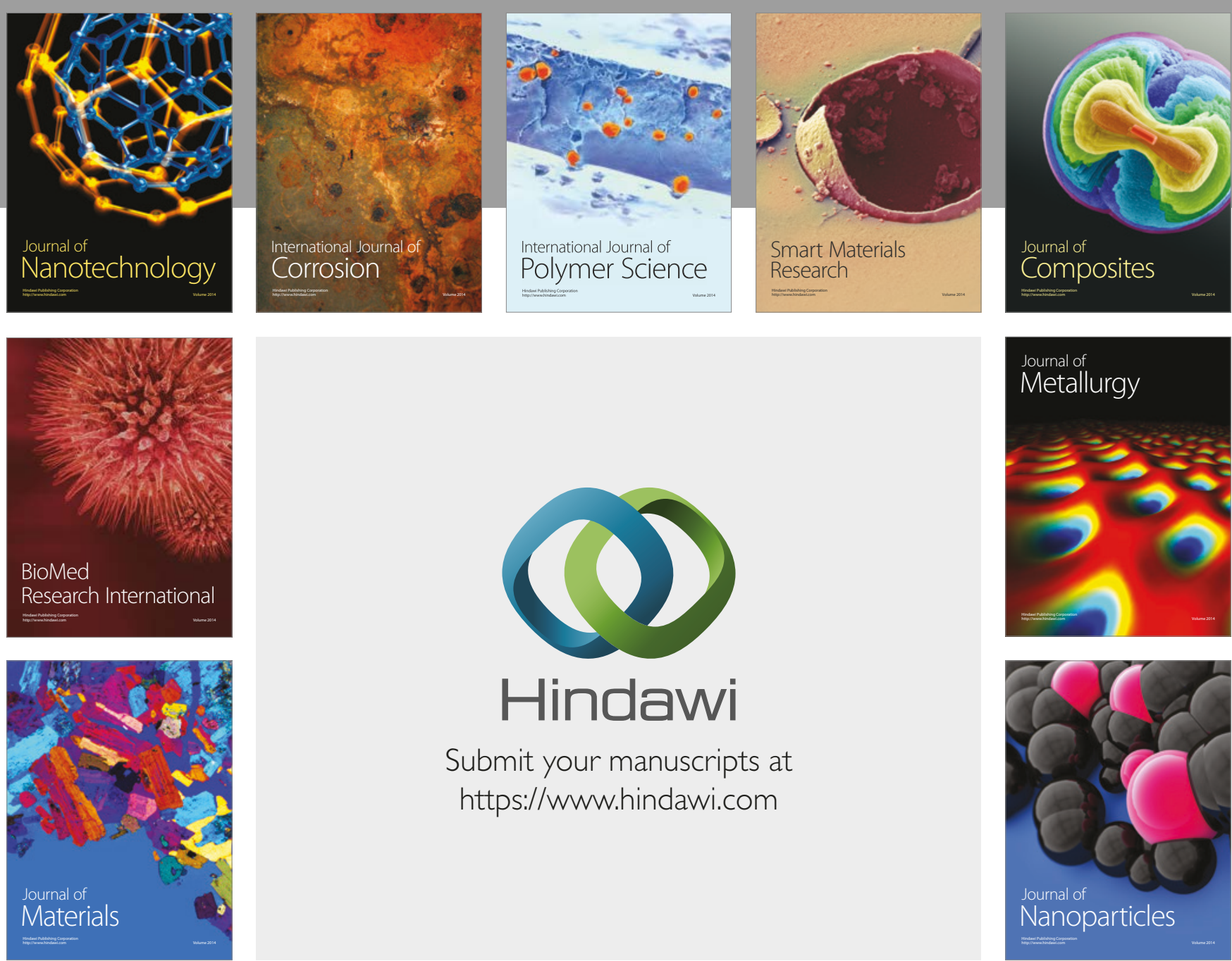

\section{Hindawi}

Submit your manuscripts at

https://www.hindawi.com
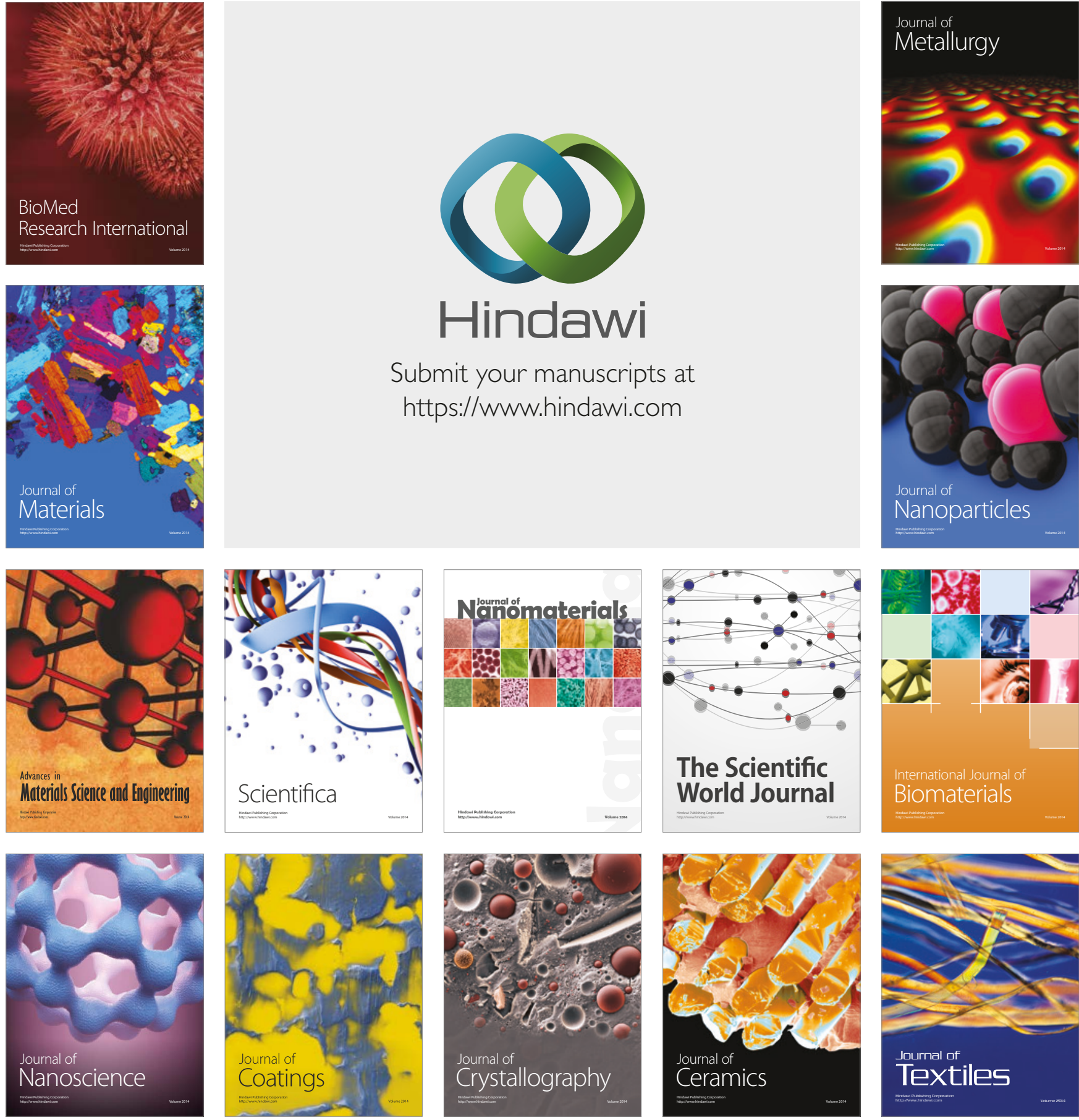

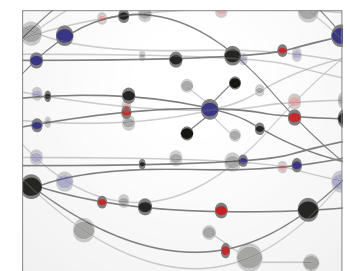

The Scientific World Journal
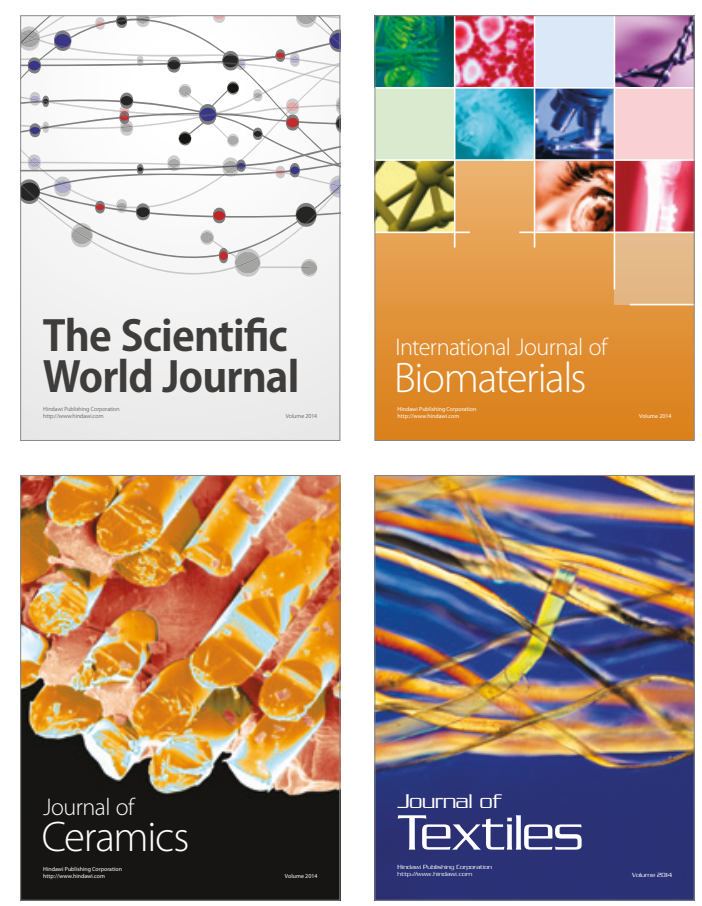